\title{
DERECHOS HUMANOS, GLOBALIZACIÓNY LOS PROCESOS DE LUCHA Y RESISTENCIA \\ DE LAS MUJERES INDÍGENAS EN AMÉRICA LATINA
}

\section{HUMAN RIGHTS, GLOBALIZATION AND THE PROCESSES OF STRUGGLE AND RESISTANCE OF INDIGENOUS WOMEN IN LATIN AMERICA}

\author{
Pilar Cruz Zúñiga \\ Universidad Pablo de Olavide, Sevilla, España \\ pgcruzun@upo.es
}

Palabras clave: derechos humanos, mujeres indígenas, luchas sociales, bienes comunes, capitalismo, globalización

Keywords: human rights, indigenous women, social struggles, common goods, capitalism, globalization

Resumen: El artículo visibiliza cómo las resistencias y las luchas de las mujeres indígenas en América Latina suponen procesos de construcción de derechos humanos al enfrentar varias lógicas de dominación: el capitalismo neoliberal y la dominación colonial y el patriarcado que lo sustentan. Utilizando la teoría crítica de derechos humanos, se enfoca menos el plano normativo-institucional y jurídico-positivo que predomina en la concepción hegemónica de derechos humanos, y se pone más la atención en la sociedad civil como fundamento de derechos humanos, por lo que las movilizaciones sociales reivindicativas son uno de los componentes importantes en el proceso de constituir derechos.

Abstract: The paper makes visible how the resistances and struggles of indigenous women in Latin America involve processes of construction of human rights by confronting various logics of domination: neoliberal capitalism and colonial domination and the patriarchy that sustain it. Using the critical theory of human rights, less focus is placed on the normative-institutional and legal-positive level that predominates in the hegemonic conception of human rights, and more attention is paid to civil society as the basis of human rights, so that social mobilizations are one of the important components in the * process of constituting rights. 


\section{Introducción}

[...] En este camino de la vida y de mi vida, de esta vida que ya no regresa, me disgusta seguir mirando y sintiendo la violencia, especialmente esa que llamamos violencia de género y que produce la muerte física, espiritual, sexual, emocional e intelectual de seres que tienen derecho a vivir con dignidad y respeto. [...] Me he sentido señalada como modosita, poco culta, miedosa, pobre e ignorante. Así me señalaron hombres y mujeres, indígenas y no indígenas, en la escuela y en la sociedad. En el Metro, en el camión, en el avión, en las calles, en las regiones, en los países, en los actos políticos, en los hoteles y hasta en las universidades me critican con la mirada de “¿A poco sabe?”. "¡Qué inteligente es! ¿A poco es india?”. "Uuhhh, ¡es feminista!, ¿es intelectual?". "Uy, pero es de izquierda, ¿o acaso es priista?". En cada mirada inquisitiva percibo sus mentes y sus imaginarios, sus referentes y sus ausentes.

Martha Sánchez Néstor (2011)1

En las últimas décadas, frente al proceso de globalización hegemónica del capital y sus manifestaciones a nivel local y global, diversos pueblos y movimientos sociales no dejan de confrontarlo y le van plantando cara en un combate desigual por las distintas regiones del mundo, siendo a menudo desacreditados por considerárseles un freno al desarrollo. En las siguientes páginas el foco de atención lo situó en América Latina, donde las luchas y resistencias de los pueblos indígenas y campesinos en defensa de sus territorios y formas de vida -con destacada participación de las mujeres-, además de desafiar los cimientos jurídicos y políticos del

1. Mujer indígena amuzga, activista y feminista de Xochistlahuaca (Guerrero, México), muy reconocida por su destacada trayectoria en defensa de las mujeres indígenas, falleció en julio de 2021.
Estado, no tienen un amplio respaldo social y les conlleva amenazas, criminalización e incluso ser asesinadas por el desprestigio y estigmatización que se hace de las personas defensoras de derechos humanos. Esas luchas y las sentencias favorables que eventualmente obtengan en su defensa tras largos procesos judiciales, se ven condicionadas porque las políticas y las prácticas que emanan de los gobiernos (con independencia de su tendencia ideológica), tienden a favorecer la extensión del modelo hegemónico de desarrollo, la libre circulación del capital y las empresas (nacionales y transnacionales) para extraer de una región rica en recursos naturales las commodities (materias primas), vendidas con altos precios en los mercados internacionales durante varios lustros del siglo XXI. ${ }^{2}$

Los pueblos indígenas son hoy algo más del $6 \%$ de la población mundial, y tienen una trayectoria de lucha y resistencias histórica para defender sus formas de vida y sus territorios donde protegen el $80 \%$ de biodiversidad que persiste en la Tierra, ${ }^{3}$ al plantear cosmovisiones distintas a la hegemónica occidental y luchar por construir realidades y formas de organización que no impliquen la depredación y destrucción de la naturaleza. En este sentido, tras décadas de postergación -y desprecio, habría que añadir- desde finales del siglo XX

2. Del rol estatal y las políticas de desarrollo en América Latina ver, por ejemplo, Cuevas y Julián (2018) y Gudynas (2018 y 2019).

3. Según el Banco Mundial (2021), en el mundo "hay aproximadamente 476 millones de indígenas en más de 90 países. Si bien constituyen más del $6 \%$ de la población mundial, representan alrededor del $15 \%$ de las personas que viven en pobreza extrema [...]. Aunque los pueblos indígenas poseen, ocupan o utilizan una cuarta parte de la superficie del mundo, protegen el $80 \%$ de la biodiversidad que aún queda en el planeta". 
y lo que va del XXI los pueblos indígenas adquirieron una "remozada visibilidad" y se reconoce más "la contribución que pueden hacer para mitigar y conservar la biodiversidad" frente al cambio climático que amenaza al planeta, y "[c]omo resultado de ello, la protección de los territorios de los pueblos indígenas ha comenzado a transformarse en una cuestión fundamental no solo para ellos, sino para toda la humanidad" (CEPAL y FILAC, 2020: 15).

En este artículo la idea central es visibilizar cómo las resistencias y luchas de las mujeres indígenas en América Latina suponen procesos de construcción de derechos humanos al enfrentar varias lógicas de dominación, desde sus experiencias y referentes propios. Para ello, utilizando la teoría crítica de derechos humanos, el punto de partida es enfocar menos el plano normativo-institucional y jurídico-positivo que predomina en la concepción hegemónica de derechos humanos, y focalizar más la atención en la sociedad civil como fundamento de derechos humanos, por lo que las movilizaciones sociales reivindicativas son uno de los componentes importantes en el proceso de constituir derechos. Eso es útil para indagar cómo las formas de las luchas de las mujeres por los bienes comunes y por la supervivencia de sus comunidades enfrentan -desde sus referentes y sentires- al capitalismo en su vertiente de globalización neoliberal y la dominación coIonial y el patriarcado que lo sustentan. Es relevante además para enfocar las dificultades y desafíos de esas luchas y los riesgos que plantea para las propias mujeres indígenas y sus pueblos, porque a menudo son descalificados por ir contra el progreso y son tachados de terroristas.

Para posibilitar tal análisis retomo algunas de las ideas que expuse en la mesa redonda celebrada el 4 de julio de 2019 en Sevilla, en el I Congreso "Derechos humanos y globalización", y a partir de ellas profundizo en aspectos que buscan dar una respuesta más amplia principalmente a la tercera de las seis cuestiones que, en aquella ocasión, nos formuló el organizador y moderador de la mesa David Sánchez Rubio: "Desde el punto de vista intercultural, ¿qué pueden aportar los pueblos indígenas y sus proyectos de vida, cosmovisiones y su modo de entender la lucha por la dignidad de cara a un mundo en el que quepan muchos mundos y desde procesos de reconocimiento de la diversidad incluyentes y no excluyentes?" (comunicación personal, 4 de julio, 2019). Los problemas claves de las seis preguntas del dicha Mesa -ver el artículo de D. Sánchez Rubio en este dossier- son los hilos conductores que uso para elaborar la reflexión analítica del presente artículo, donde combino los aspectos de orden teórico con insumos de las luchas y resistencias indígenas en América Latina, privilegiando las acciones de las mujeres, por lo que la metodología utilizada es cualitativa con énfasis en la revisión bibliográfica.

El artículo se estructura en seis apartados, incluyendo esta breve Introducción que está enumerada como el primero de ellos. En el segundo, destaco los principales aportes de la teoría crítica de los derechos humanos e incido en la necesidad de ampliar el imaginario hegemónico, universalista y reducido (mono-cultural) que derechos humanos tiene para así posibilitar más maneras de "leer" y visibilizar la participación de las mujeres indígenas en las luchas y resistencia de sus pueblos. En el tercero, señalo aspectos clave de la expansión capitalista como contexto donde situar los conflictos socioambientales y las luchas y resistencias de los pueblos y las mujeres indígenas que analizo en el cuarto 
apartado, principalmente en los ámbitos de movilización, demandas y reclamaciones jurídicas y la construcción de nexos de apoyo que busca enfrentar la violencia al interior y exterior de sus pueblos. El quinto apartado corresponde a una reflexión final y el sexto a la bibliografía.

Con este estudio aún preliminar busco aproximar las experiencias situadas y complejas de las propias mujeres -en sus compromisos políticos y de liderazgos desde sus organizaciones, pero también en sus cosmovisiones y luchas cotidianas-, para que sean valoradas como espacios que van construyendo reconocimiento pese a los elevados riesgos que asumen y se evite descalificarlos desde "miradas" que expresan violencias paternalista, machista, racista, clasista y colonial, como las que describe Martha Sánchez Néstor (2011) en la cita al inicio de esta Introducción. Además me interesa propiciar una reflexión acerca de esos procesos y experiencias de América Latina que se construyen desde abajo, desde los márgenes y desde pueblos históricamente oprimidos, que con sus acciones y los apoyos solidarios que reciben cuestionan y también transforman -poco a poco- las realidades instauradas en las cuales predomina como meta y valores fundamentales el progreso, el desarrollo, la acumulación y la obtención del máximo beneficio y donde los seres humanos son un recurso más de explotación.

\section{La importancia de la perspectiva crítica de derechos humanos}

Antes de indicar los aspectos relevantes de la perspectiva crítica de derechos humanos, es importante destacar varias consideraciones que plantea la implementación de derechos humanos para los pueblos indígenas porque suponen situaciones problemáticas y reconocimientos de derecho tardíos.

La primera de ellas se refiere a cómo se reconoce a estos pueblos y sus territorios, sometidos desde el periodo de los "grandes descubrimientos europeos" en el siglo $\mathrm{XV}$, por procesos impuestos y unidireccionales desde los estados colonizadores europeos, los estados coloniales sucesores y los estados nacionales surgidos a partir del siglo XIX hasta hoy. Debido a la limitada extensión de este artículo, para caracterizar los procesos básicos es útil citar a Rodolfo Stavenhagen (2006: 22-23):

Al asumir unilateralmente el derecho de conquista, la Corona [de España] dejó sin derechos propios a los autóctonos, salvo los que la propia Corona tuviera la gracia de concederles. Con algunas variantes, las demás potencias europeas hicieron lo suyo en las tierras que les tocó "civilizar". Ya entrado el siglo XIX los estados nacionales, herederos de aquellos imperios coloniales, se ocuparon de sujetar o "pacificar" a lo que quedaba de los pueblos "bárbaros" y "salvajes" que se resistían a ser dominados y despojados. En las Américas en el siglo XX, esta política llamóse indigenismo y el proceso de asimilar e incorporar a estos pueblos indígenas al estado recibió el nombre de desarrollo. [...] Las complicadas relaciones entre los pueblos indígenas originarios y los estados nacionales que surgieron de la caída y fragmentación de los imperios coloniales constituyen hasta la actualidad el marco de referencia de la problemática de los derechos humanos y los pueblos indígenas.

Además en los países latinoamericanos las leyes y los estados que las garantizan son frágiles o se alían a los intereses de 
los poderosos e inclusive las propias sociedades se han constituido con "brutales procesos de genocidio y etnocidio que la historia oficial invisibiliza como 'descubrimiento', 'colonización', 'expansión de la frontera' y 'modernización”, normalizando y naturalizando esas violencias al considerarlas como inevitables y necesarias, no reconociendo ni reparando los reclamos que frente a esos crímenes hacen los pueblos indígenas (Gallardo, 2008: 253).

Una segunda se refiere al tardío el reconocimiento normativo de los derechos de los pueblos indígenas. En el sistema de Naciones Unidas desde la década de 1950 "comenzaron a moverse algunas cosas" y en 1957 la Organización Internacional del Trabajo (OIT) "adoptó el Convenio 107 sobre poblaciones indígenas y tribales en países independientes, que fue modificado en 1989 y se conoce ahora como el Convenio 169" (Stavenhagen, 2006: 23), por el cual se les reconoce como titulares de derechos. En 2007143 países del mundo "reconocieron normas mínimas para su supervivencia, dignidad y bienestar, a través de la Declaración de las Naciones Unidas sobre los Derechos de los Pueblos Indígenas [...] tras tantas luchas, habían conquistado su derecho a la autodeterminación"; en 2014 esos mismos estados, presentes en la Conferencia Mundial sobre los Pueblos Indígenas reafirmaron en el documento final su "solemne compromiso de respetar, promover, impulsar y no menoscabar en modo alguno los derechos de los pueblos indígenas y de defender los principios de la Declaración" (CEPAL y FILAC, 2020: 15). También en los países de América Latina y el Caribe, se registran avances como el heterogéneo "reconocimiento constitucional de los pueblos indígenas en la mayoría de los países de la región (con excepción de Chile, Costa Rica y el Uruguay) y, en particular, la elevación a rango constitucional de sus derechos territoriales", siendo común "el reconocimiento del carácter colectivo de la propiedad de la tierra, en consistencia con los estándares internacionales en la materia" (CEPAL y FILAC, 2020: 74).

La tercera es de índole práctica ya que pese a esos adelantos normativos, es limitada la incorporación y garantía de los derechos colectivos. Como hace años escribió Stavenhagen, para los pueblos indígenas "el reconocimiento de sus derechos colectivos tiene diversas vertientes: territoriales, jurídicas, culturales, sociales, económicas y políticas", y para muchos de ellos "la recuperación y la protección de sus tierras y de su hábitat son condición sine qua non de su supervivencia como colectividades identificables" (2006: 26). En particular, se incumple el control y manejo por los propios pueblos indígenas de sus espacios territoriales (la autodeterminación, autonomía) en un contexto de globalización económica y creciente extractivismo impulsado por el Estado, con la consiguiente violencia y persecución de las protestas. CEPAL y FILAC señalan claramente el panorama actual y las razones:

Pese al extendido reconocimiento de los derechos territoriales, en la práctica se observa una gran brecha en la implementación de la obligación estatal de demarcar, titular y sanear las tierras indígenas, principal mecanismo para efectivizar estos derechos, dado que los países de la región, de manera generalizada, no han adecuado sus marcos normativos e institucionales [...]. Los pueblos indígenas deben enfrentar entonces múltiples obstáculos para la formalización de la tenencia de sus tierras y territorios [...]. El impacto de la globalización econó- 
mica y el desarrollo de la industria extractiva en todas las economías del continente ha inducido un proceso de involución en los marcos normativos, que se expresa principalmente en la adopción de leyes sectoriales que subordinan los derechos indígenas a los intereses empresariales y estatales, y en brechas de implementación, en particular en la delimitación, demarcación y titulación de las tierras (CEPAL y FILAC, 2020: 74)

Por eso resultan limitados el consentimiento libre, previo e informado, y la consulta previa ${ }^{4}$ como mecanismo para resguardar los derechos de los pueblos indígenas sobre sus territorios, tierras y recursos naturales, apreciándose la tendencia a aludirlos como si se tratase de dos derechos independientes por parte de los organismos internacionales, los Gobiernos y la sociedad civil indígena y no indígena, al relativizar su "conexión indisoluble", pero también por "la burocratización de los mecanismos de implementación y a los cuestionamientos de los propios pueblos indígenas que demandan el respeto a sus decisiones autónomas" (CEPAL y FILAC, 2020: 75).

Ahora paso a señalar -en forma resumida- elementos clave de derechos humanos desde la perspectiva crítica y basándome principalmente en los aportes del chileno Helio Gallardo y el sevillano David Sánchez Rubio. ${ }^{5}$ Considero que son importantes para ampliar y no circunscri-

4. La consulta consta en las constituciones de Bolivia, Ecuador, México y Venezuela.

5. Por la limitación de espacio, uso un solo libro por cada autor; otros títulos suyos o de más autores de interés constan en la bibliografía final de esos libros. Ambos autores podrían inscribirse en "la búsqueda de una concepción contrahegemónica de los derechos humanos" que señala Santos (2018: 209); él además indica que hay diferentes concepciones de derechos humanos. bir derechos humanos sólo a su versión liberal y burguesa, jurídico-institucional y desde un sujeto abstracto -entre otros aspectos simplificadores-, así como para ver las limitaciones que derechos humanos tienen en contextos con más referentes que los predominantes de Occidente y donde la asimetría y desigualdad son manifiestas y las instituciones del Estado están debilitadas y condicionadas, mientras se suceden innumerables reclamos y movilizaciones de la sociedad civil. Considero que estos elementos contribuyen a que el horizonte del análisis se extienda para el estudiar las luchas y resistencias de los pueblos indígenas, especialmente la de las mujeres.

Como sintetiza Sánchez Rubio, la noción más extendida de derechos humanos considera que éstos se asientan en las normativas, la capacidad de las instituciones para garantizarlas (el Estado, principalmente) y en ciertos valores que le dan fundamento como la libertad, igualdad y solidaridad; ${ }^{6}$ sin embargo, esta versión es limitada "por ser excesivamente estatalista, normativista, burocrática y post-violatoria" (2018: 5). Él -al igual que Gallardo (2008) - inciden en ampliar esa noción hegemónica de derechos desde la cual entendemos que nos son otorgados por la "condición innata" de ser seres humanos, tal como proclaman las constituciones y leyes de los países y tratados internacionales en esta materia, encabezados por el

6. Estos elementos están, por ejemplo, en la definición de Antonio Enrique Pérez Luño de derechos humanos: son "un conjunto de instituciones y facultades que en cada momento histórico concretizan los valores de igualdad, libertad y dignidad humanas, precisando ser positivizados en normas jurídicas tanto de carácter nacional como internacional" (1999, citado en Sánchez Rubio, 2018: 139). 
sistema de Naciones Unidas. ${ }^{7}$ Para ello, un elemento clave es apelar a la concepción sociohistórica y entender derechos humanos como procesos de lucha social es decir, "son producidos y sostenidos por los seres humanos en su historia económica, sexual, política, espiritual" (Gallardo, 2008: 5), y por eso están anclados en la sociabilidad humana o tramas sociales -en la terminología de Gallardo (2008)que permiten dominar, pero también revertir esa dominación al empoderar y generar autonomía y autoestima. En palabras del autor chileno:

Determinar derechos humanos como un fenómeno político significa radicarlos en la sociabilidad humana, trazar su fundamento sociohistórico e integrador y, en el mismo movimiento, estimar su universalidad como proyecto, irradiación y proceso. [...] Construir una cultura de derechos humanos exige así un esfuerzo político permanente ya que ellos no pueden derivarse de ninguna condición innata o de la inercia de las instituciones (Gallardo, 2008: 5)

Esta concepción sociohistórica explica o ayuda a entender la distancia entre lo que dicen y hacen en derechos humanos principalmente las instituciones, o el abismo entre la teoría y su práctica cuando hay infinidad de leyes y normativas que los garantiza mientras resultan exiguos los niveles de justicia y restitución cuando hay violaciones de derechos humanos. Como resalta Sánchez Rubio, son muy pocos los estudios que mencio-

7. Ello se aprecia en los considerandos de la IX Conferencia Internacional Americana (1948), reunida en Bogotá al adoptar la Declaración Americana de los Derechos y Deberes del Hombre: "Que, en repetidas ocasiones, los Estados americanos han reconocido que los derechos esenciales del hombre no nacen del hecho de ser nacional de determinado Estado sino que tienen como fundamento los atributos de la persona humana". nan esa distancia y llama a no naturalizarla y considerarla indiscutible (es "una de las razones que justifican la indolencia y la pasividad"), proponiendo en su lugar una noción compleja de derechos humanos que combine la dimensión jurídica con la social y la política desde una sensibilidad y "modo maximalista", cuyo referente sean "las personas victimizadas, oprimidas y vulnerabilizadas", implementándose "una estructura de reconocimiento y eficacia de derechos humanos multigarantista y pluri-espacial, que pueden resumirse en la expresión de Helio Gallardo de que los 'derechos humanos deben ser a tiempo completo y en todo lugar'" (Sánchez Rubio, 2018: 10). Implica entonces tejer espacios relacionales o tramas sociales que construyan y garanticen derechos humanos en distinto nivel y espacio, involucrando a las instituciones y la sociedad civil no sólo en los ámbitos formales e institucionales sino también cotidianos, en el plano individual y colectivo, a pesar de las dificultades existentes en determinados contextos, siendo importante "nutrir una cultura que empodere y transfiera poderes a las mayorías populares y subalternas" (Sánchez Rubio, 2018: 25). Gallardo expresamente menciona:

La concepción sociohistórica indica que el fundamento de derechos humanos está en otro mundo posible, derivado de las luchas de las diversas sociedades civiles emergentes modernas, y en la capacidad de esas luchas para conseguir la judicialización de sus demandas y la incorporación de su sensibilidad específica o peculiar en la cultura reinante y en la cotidianidad que se sigue de ella y que potencia su reproducción (2008: 5)

Ambos autores coinciden en destacar la importancia de las luchas sociales para 
generar derechos humanos, para no quedarse solo en un nivel delegativo que acude a los aparatos del Estado para garantizarlos por medio de la normatividad y la efectividad jurídica, ${ }^{8}$ por las limitaciones que tienen. Porque en algunos contextos el Estado tiene una fuerte presencia y en otros sus instituciones son débiles, estando condicionadas por "la falta de presupuesto, por políticas de privatización o por desentendimiento", pero en unos y otros contextos derechos humanos se defienden desde una concepción post-violatoria porque "parece que sólo existen una vez que han sido conculcados" (Sánchez Rubio, 2018: 143). Gallardo destaca asimismo que "Mercado y Estado aparecen, en la coyuntura, como enemigos explícitos de derechos humanos desplazados por la búsqueda de un crecimiento que beneficia a minorías y discrimina a sectores mayoritarios de la población [...] como las condiciones de reproducción del hábitat natural", por lo que las lógicas complementarias entre uno y otro "los muestra así, estructuralmente, como explícitos núcleos y dispositivos de violencias" (2008: 54) (las cursivas son de Gallardo).

Sánchez Rubio condensa en dos los tipos de lucha por derechos humanos: 1) la que se hace a través de los movimientos sociales, generando con ello derechos humanos "desde poderes constituyentes populares con una mayor fuerza colectiva transformadora" y, 2) la "lucha relacional del día a día", donde derechos humanos "son ejercidos por poderes instituyentes

8. Por ejemplo, el artículo 2 de la conocida como Declaración sobre los Defensores de los Derechos Humanos (Naciones Unidas, 1999), establece que los Estados tienen la "responsabilidad primordial" y el "deber de proteger, promover y hacer efectivos todos los derechos humanos y las libertades fundamentales" (Naciones Unidas, 1999: 3). más 'cotidianistas' expresados con la potentia individual y personal y las acciones particulares desenvueltas por cada persona relacional y sociomaterialmente" (2018: 49). Precisamente por esa doble causa que deriva de las luchas sociales, el autor sevillano considera que "para hacer efectivo los derechos humanos se precisa la creación de sistemas de garantías", plurales y múltiples "que funcionen con las actuaciones y acciones humanas de defensa y lucha y reivindicación", que complementen y combinen "tanto las actuaciones como los dispositivos estatales y sobre la base de las relaciones y tramas sociales públicas, estatales y privadas", para que la sociedad civil y el pueblo recuperen su rol de actores "que construyen garantías sociales, la mayoría de ellas respaldadas por los textos constitucionales, pero anuladas por la inactividad, inamovilidad y la inacción de las instancias estatales" (Sánchez Rubio, 2018: 55-57).

Los aportes de Sánchez Rubio sobre las luchas colectivas y los sistemas de garantías amplían las dimensiones "c" y "d" de los elementos que estructuran derechos humanos -los cinco que dedujo de lo señalado por H. Gallardo (2008) y el sexto que él añade-:

a) la reflexión filosófica o dimensión doctrinal, b) el reconocimiento jurídico-positivo e institucional a nivel nacional e internacional, c) la eficacia y efectividad jurídica estatal (políticas públicas y sentencias judiciales), d) la lucha social, y e) la sensibilidad sociocultural. [...] f) los valores como la libertad, la igualdad, la dignidad, la solidaridad, la vida humana y de la naturaleza, que en forma de reglas y principios se objetivan en normas, se reflexionan e interpretan filosóficamente, doctrinal y teóricamente en su parte argumentativa y discursiva y, además se reivindican por los movimientos sociales (Sánchez Rubio, 2018: 139-140). 
Un ejemplo de la ampliación de la dimensión "c" con sistemas de garantías jurídicas no estatales está en los países de América Latina con la existencia de una dimensión jurídica no estatal que es la que plantean los colectivos como los pueblos indígenas, los grupos afrodescendientes o el Movimento Sim Terra (MST): "se auto-reorganizan y autorregulan desde lógicas emancipadoras con modos de resolución de conflictos y garantías de derechos a partir de paradigmas jurídicos no estatales o que se complementan con ellos"; este último caso corresponde al denominado "nuevo constitucionalismo latinoamericano" que por medio de los "Estados plurinacionales" (variados aunque con cierta afinidad), han reconocido "nuevos derechos vinculados con la dimensión multiétnica y plurinacional de sus estados" (Sánchez Rubio, 2018: 49 y 56-57). Ejemplos de reconocimientos de estas últimas dimensiones son la inclusión -con perspectivas más biocéntricas que antropocéntricas- de la naturaleza - Pachamama como sujeto de derechos en la Constitución de Ecuador de 2008; la Constitución de Bolivia 2009 y las reformas legislativas de 2010 y, sobre todo, la de 2012 con Ley de la Madre Tierra que han posibilitado un resultado similar; la sentencia de la Corte Constitucional de Colombia que en 2016 otorgó derechos al río Atrato o el fallo de la Corte Interamericana de Derechos Humanos (CIDH) que en abril de 2020 declara a Argentina "responsable internacionalmente por la violación de los derechos a la propiedad comunitaria indígena, a la identidad cultural, a un medio ambiente sano, a la alimentación y al agua" (Secretaría de la $\mathrm{CIDH}, 2020$ ).

La complejización de derechos humanos hasta aquí expuesta es emancipatoria porque amplía y cuestiona la matriz hegemónica de derechos humanos al mostrar causas de derechos radicadas en procesos sociales, en dimensiones no jurídicas y reconocimientos multiétnicos y plurinacionales, e incluso aluden -en palabras de Sánchez Rubio- "a esa dimensión o componente utópico positivo que ayuda a la gente a caminar frente a todo aquello que achica, reduce o aniquila la condición plural, abierta, procesual y diferenciada de lo humano (2018: 142). Confronta a esa matriz liberal que -como bien la caracteriza Santos- "concibe a los derechos humanos como derechos individuales, y privilegia los derechos civiles y políticos", y al discurso y sentido común convencional de derechos humanos que poco a poco "se fue convirtiendo en el discurso de la dignidad humana, consonante con la política liberal, el desarrollo capitalista y sus distintas metamorfosis [...] y con el colonialismo, asimismo metamorfoseado" (Santos, 2018: 210 y 214).

No obstante, los procesos de reconocimiento de derechos humanos no están exentos de tensiones y ambivalencias, a la vez que están dotados de recursos y garantías mínimas para su implementación por parte de los estados. Por ejemplo, Santos señala que se los apela en "situaciones de erosión o de violación particularmente grave de los derechos de ciudadanía. Los derechos humanos emergen como el umbral más bajo de inclusión, un movimiento descendente desde la comunidad más densa de los ciudadanos a la comunidad más diluida de la humanidad", pero también el que al adoptarse la Declaración Universal de Derechos Humanos por la Asamblea General de las Naciones Unidas (1948) solo se reconoce dos sujetos de derechos: el individuo y el Estado, planteándose una tensión entre 
los derechos individuales y los derechos colectivos (Santos, 2018: 215). Por lo abordado al inicio de este apartado, para el caso de los pueblos indígenas de América Latina tal tensión no se da sólo por las dificultades de implementar esos derechos colectivos, sino porque son pueblos cuyos derechos han sido y son postergados en la práctica, pese a los adelantos normativos internacionales y nacionales proclamados o legislados y, porque también el peso de su implementación recae en el Estado, que es quien muchas veces perpetra las violaciones de derechos humanos, como se verá en el apartado cuarto.

\section{Expansión del capitalismo y control de la pluralidad $\mathrm{y}$ diversidad humanas $\mathrm{y}$ naturales}

A continuación presento un apretado resumen que ayude a comprender lo que constituye el capitalismo y su expansión, para así entender sus contradicciones pero, sobre todo, los conflictos sociales y ambientales que genera en los países centrales y periféricos del sistema-mundo moderno -surgido en el siglo XVI-, en el cual la economía-mundo capitalista siempre es y ha sido la predominante (Wallerstain, 2005). Pese a la simplificación analítica -por el poco espacio disponible en este artículo- sirve de "marco" necesario para situar los conflictos sociales y las resistencias de las mujeres indígenas que abordaré en la siguiente sección.

La extensión en forma hegemónica del mercado desde el siglo $X X^{9}$ que acabó

9. Karl Polanyi señaló este proceso y una relevante distinción entre "economía sustancial y economía formal", explicando cómo la segunda siendo el principio básico de las sociedades capitalistas con la racionalidad instrumental y sus procesos de mercantilización de la vida, contribuyen a que no consideremos que "la Humanidad, la Naturaleza y la Tierra forman conjuntos interdependientes" y que más bien hayamos normalizado "que todas las facetas de la existencia social han ido quedando reducidas al mecanismo de la oferta y de la demanda, regulado por el sistema de precios", y son ya muy pocos los espacios "que se salvan del proceso de subsunción formal del capital" (Sánchez Rubio y Solórzano, 2004: 18 y 21).

El proceso de globalización contemporánea del capital envuelve también la imposición y "cultivo de lo uniforme, que presupone la homogeneidad y la destrucción de la diversidad, tanto social como de la naturaleza", por lo que la violencia en sus múltiples formas y niveles es el recurso que el poder usa para ejercer el control y crear monopolios sobre la vida y los recursos vivos, como lo señala desde hace años Vandana Shiva (2001 y 2003, citada en Sánchez Rubio y Solórzano, 2004 : 25). ${ }^{10}$ La uniformización se impone en oleadas globalizadoras que comprenden

pasó a "convertirse en la última instancia de la realidad socio-histórica" de las sociedades modernas capitalistas (Sánchez Rubio y Solórzano (2004: 20-21). Del auge del capitalismo desde el "largo" siglo XVI (1450-1648) y su expansión hasta hoy por fronteras "esenciales para la creación de formas de naturaleza barata específicas para el capitalismo: los 'Four Cheaps' del trabajo, alimentos, energía y materias primas", ver Jason W. Moore (2016).

10. Sánchez Rubio y Solórzano (2004: 25) explican cómo la violencia se da "a) en el nivel político, mediante el uso de la fuerza, el control y la centralización; b) como violencia ecológica contra las diversas especies de la naturaleza [...]; y c) como violencia social y cultural". 
el colonialismo, el desarrollismo y el libre comercio (la actual y "la última oleada que también se entiende como una segunda colonización" del capital), como en base a Shiva resumen Sánchez Rubio y Solórzano (2004: 26). Esta segunda coIonización corresponde al neoliberalismo que "tiende a significar una ideología conservadora que enfatiza la importancia del libre mercado" (Wallerstain, 2005: 61), desplegado desde el denominado "Consenso de Washington en la década de 1980 e impulsado por fuerzas económicas globales con el apoyo de los gobiernos de muy pocos estados (por ejemplo, Estados Unidos, Reino Unido, la Unión Europea) y por esa "Nueva Trinidad Institucional" que constituyen el Fondo Monetario Internacional (FMI), la Organización de Mundial de Comercio (OMC) y el Banco Mundial (BM), "cuya función es la de controlar y dominar las relaciones económicas que comprometen al mundo empobrecido (Tercer Mundo)", como definen Sánchez Rubio y Solórzano (2004: 29). Un ejemplo son la implementación en los países de América Latina desde las "nuevas democracias" los dogmáticos paquetes de reforma neoliberales o programas de ajustes estructurales recetados a aplicar periódicamente por el FMI y el BM en las décadas de 1980-1990 para estabilizar, regular y reorientar la economía al libre mercado, lo que provocó crisis económica, fragilización de la política, privatizaciones, flexibilización laboral y empobrecimiento generalizado en la región (Galafassi, 2018; Rojas, 2018).

El capitalismo además no es sólo un sistema económico, sino "una relación social que somete a los seres humanos y la naturaleza a la lógica de la acumulación", como explicó François Houtart (2017: 4). Y parte del proceso de establecimien- to de lo uniforme es la expansión de la comprensión occidental del mundo y de su concepción de la racionalidad, de la ciencia, la cultura..., en definitiva, del ser, del saber, del poder y del hacer occidental en forma hegemónica por el mundo (Sánchez Rubio, 2018). Es decir, ese "imperialismo cultural" sobre el que llamaron la atención desde la Escuela de Frankfurt para referirse a la dominación que se extendía desde los países centrales a los periféricos o dependientes. Ya lo identificó Rosa Luxemburg al manifestar que "Io que diferencia a la producción capitalista de todos los sistemas anteriores es que tiende a expandirse mecánicamente a toda la superficie del planeta invalidando sistemas preexistentes" ([1913] 1967, citada en Rojas, 2018: 150).

Las dinámicas del funcionamiento del capitalismo, en su fase de globalización neoliberal y la obtención del máximo beneficio y el predominio del dinero, además de la extensión de la propiedad, arrasan con la pluralidad y la diversidad humanas, culturales y naturales, al dirigir estrategias para convertir y mercantilizar "la naturaleza y la humanidad en formas de capitales naturales y capitales humanos" (Sánchez Rubio y Solórzano, 2004: 32) y la búsqueda constante de nuevos espacios de donde extraer ganancias. Como escribe Moore (2016: 169): "ese proceso de conseguir naturalezas extra-humanas -y humanas también- para trabajar por costes mínimos de dinero y energía es la historia de las grandes fronteras mercantiles del capitalismo y, con ello, de las largas olas de acumulación del capitalismo". Además, Yayo Herrero desde el ecofeminismo, llama la atención sobre "el dualismo occidental que fractura la cultura de la naturaleza y los cuerpos", que crea seres privilegiados que viven como si no hubie- 
ra límites y hace que la política y la economía se organicen "como si esos seres privilegiados fuesen el sujeto universal. El problema es que esa fantasía sólo puede mantenerse porque en espacios invisibles y subyugados, otras personas y otros territorios se ocupan, de forma no libre, de reproducir la existencia" (Herrero, 2019, citada en Casanova, 2021: 143-144).

Entre las varias estrategias que el poder y el capital llevan adelante desde hace siglos a nivel local y global -y usando siempre la violencia en su múltiples formas- está la explotación de los recursos naturales, la "acumulación por desposesión" que amplía los ámbitos y esferas de mercantilización (Harvey, 2003) hasta los hoy denominados extractivismos. Estos últimos suponen la apropiación intensiva en gran volumen y alta intensidad para su exportación, como materias primas, de las explotaciones mineras, de hidrocarburos, las madereras, los monocultivos así como la concesión del agua de los ríos y la construcción de grandes infraestructuras para el desarrollo industrial, turístico, urbano, portuario (los megaproyectos) por los estados y las empresas transnacionales, sin tener en consideración los costos sociales y ecológicos para las comunidades y la naturaleza, incluido el cambio climático (Acosta, 2019; Galafassi y Riff, 2018; Gudynas, 2018 y 2019; Stavenhagen, 2006). Tampoco hay que olvidar mencionar la utilización de recursos como el Acuerdo de la OMC sobre los Aspectos de los Derechos de Propiedad Intelectual relacionados con el Comercio (Acuerdo sobre los ADPIC [TRIPS por su denominación en inglés]), que "como instrumento jurídico con fines comerciales, genera derechos monopólicos en favor de las organizaciones privadas de investigación y las empresas más poderosas" en áreas como los de "la agricultura, la acuicultura, la ganadería, la industria farmacéutica, etc.: herbicidas, pesticidas, productos transgénicos animales y vegetales, etc." (Sánchez Rubio y Solórzano, 2004: 32 y 33). ${ }^{11}$

Desde mediados de la década de 1950 en la naturaleza aparecen los efectos de estas diversas formas de expansión de la economía de mercado moderna, que se intensifican a partir de la década de 1970 , cuando se inicia la celebración periódica de las Cumbres de la Tierra y surge un entramado de entidades y organismos internacionales que hegemonizan hasta ahora las normativas y acciones para enfrentar la crisis medioambiental; a partir de la década de 1990 hay sectores más críticos con el modelo de desarrollo y crecimiento que acarrea el deterioro y la devastación de los territorios, pero también la apropiación y despojo en zonas y espacios de vida no incorporadas plenamente a las lógicas del capital, sobre todo en las áreas periféricas del sistema-mundo como los países del Sur -en América Latina, por ejemploantes que los del Norte (D'Amigo y Agoglia, 2019; Gudynas, 2019). ${ }^{12}$ Además,

11. De la colisión entre el derecho a la salud y el derecho de propiedad intelectual que favorece a la industria farmacéutica frente a los países en desarrollo, ver Allard (2015) y de las tensiones en la liberalización de transgénicos en Brasil, México y Argentina, a Berger y Carrizo (2018).

12. D'Amigo y Agoglia llaman "ambientalismo hegemónico" a aquel con "capacidad para construir amplios consensos (prácticos y discursivos) a nivel mundial en torno a la problemática ambiental" y como "corriente ambiental crítica" a aquella donde "abrevan múltiples vertientes teóricas como la ecología política (latinoamericana y de otras latitudes), el marxismo ecológico, el ecofeminismo, las propuestas del buen vivir y el posdesarrollo, entre otras, y que no por azar han tenido un amplio tratamiento en la región latinoamericana" 
como describe Klaus Dörre, "la gran crisis de 2008-2009 demuestra que esta interrelación entre crecimiento económico y destrucción ecológica ha llegado a un punto histórico de ruptura" y mientras en los centros capitalistas "todavía se puede generar crecimiento económico, las fuerzas de destrucción ecológica devoran la ganancia de bienestar dividida de forma sumamente desigual", por lo que hoy en día es "una ilusión problemática" (2018: 71-72).

Este complejo marco de la globalización neoliberal estaría incompleto si no se mencionan al menos dos aspectos importantes principalmente en áreas no centrales del sistema-mundo: por un lado, el rol que tiene el Estado en el desarroIlo capitalista y, por otro, los procesos de conflictividad y rechazo. En el contexto de la globalización el Estado no sólo redefine sus atribuciones, sino que pasa a ser un aliado imprescindible para los procesos de reproducción del capital, el mercado y las empresas transnacionales, registrándose "variadas modalidades de intervención del Estado (neoliberal, desarrollista, populista, etc.), las que pueden ir desde la prescindencia y el retroceso del sector público, hasta un papel de Estado empresario, pasando por un rol de entidad reguladora o de planificador estratégico de carácter sectorial" (Cuevas y Julián, 2018: 17-19). Además -como lo mencioné en el apartado anterior-, el Estado sigue siendo el garante de las leyes y del reconocimiento formal de derechos y de implementar

(2019: 106, 108-109). Para Gudynas (2018: 186), los "grandes cuestionamientos ambientales contra el desarrollo como crecimiento económico en la década de 1970", no desencadenaron los "cambios radicales" que se esperaba y derivaron "hacia distintas versiones oficiosas de 'desarrollo sostenible", buscando "acompasar medidas ecológicas con el crecimiento económico". las políticas públicas, lo que le otorga no sólo capacidad sancionadora, sino también la capacidad de velar o desatender los intereses de las comunidades o amparar a los sectores que detentan el poder económico.

Los conflictos y procesos de movilización social surgen más en los países periféricos que en los centrales ante los "cercamientos" del capitalismo que amenaza con arrebatar a la sociedad "aquellos "bienes comunes' que habían logrado todavía mantener", permitiendo trazar una "correlación diferencial entre acumulación y conflicto social, llegando a distinguir algunos autores un nuevo ciclo de conflictos a lo largo de todo el mundo basados en la desposesión" (Galafassi, 2018: 31-32). En regiones como las de América Latina estos procesos de resistencias y movilizaciones sociales, que se levantan con más fuerza desde 1990 en un intento de subvertir la expansión y dominación del capitalismo en su versión neoliberal, dejan observar no sólo una diversidad de actores sino cómo entran en juego otros elementos interconectados y de larga duración que sustentan el capitalismo como son el colonialismo y el patriarcado. En el siguiente apartado me refiero a ellos al abordar lo que implican las resistencias y luchas de las mujeres indígenas en América Latina desde una perspectiva amplia de derechos humanos.

\section{Las resistencias y luchas de las mujeres indígenas}

Y si creen que con eso nos van a espan-
tar, les queremos decir que nos ponen más
fuertes, que nos dan más ánimo porque
en la medida de que ellos apuestan por la
muerte, nosotros seguimos apostando por la 
vida [...] Es necesario pues hermanos, hermanas, mujeres sobre todo nosotras, que estamos al frente del campo, al frente de la casa, al frente de la tierra. ¡Vean nuestra fuerza! [...] no les tendremos miedo y que viene un tiempo de nosotros los pueblos, de nosotros los pueblos indígenas! Ya basta de que sigan acabando con nosotros.

Bety Cariño, indígena mixteca, 3 de diciembre de $2009^{13}$

Es importante mencionar tres aspectos sobre la región latinoamericana antes de analizar las movilizaciones y resistencias de las mujeres indígenas.

Primero, en América Latina se aprecia un contexto históricamente caracterizado por grandes brechas sociales que se han profundizado con la pandemia por el coronavirus. Problemas estructurales como la pobreza, la desigualdad y el desempleo "avanzaron a un ritmo sin precedente", porque en 2020 según la Organización Mundial de la Salud (OMS) "en la región vivía solo el 8,4\% de la población mundial, a diciembre de ese año, se concentraban en ella el $18,6 \%$ de los contagios acumulados de COVID-19 y el $27,8 \%$ de las muertes causadas por esta enfermedad" (CEPAL, 2021: 13). Si entre 20142019, el PIB de América Latina y el Caribe "había crecido en promedio tan solo un 0,3\% por año [...] el porcentaje de pobreza extrema había aumentado del 7,8\% al $11,3 \%$ de la población y la pobreza, del 27,8\% al 30,5\%"; además los ejes estructurantes de la matriz de desigualdad ("el estrato socioeconómico, el género, la eta-

13. Extracto del discurso que pronunció en esa fecha frente a la embajada de Canadá en una protesta contra el asesinato de Mariano Abarca, indígena de la comunidad chiapaneca de Chicomuselo, asesinado por sicarios contratados por una empresa minera canadiense (El Rebozo et al., 2014: 21-22). Ella murió asesinada en 2010. pa del ciclo de vida, la condición étnicoracial, el territorio, la situación de discapacidad y el estatus migratorio, entre otros") producen "escenarios de exclusión y discriminación múltiple y simultánea”, que acentúa la vulnerabilidad ante los efectos sanitarios, sociales y económicos del COVID-19, registrándose también un descenso importante en la demanda de los productos que se exportan desde la región por las medidas adoptadas en otros países del mundo (CEPAL, 2021: 14-16). Enfrentar la pandemia es más complicado y reviste situaciones de particular desventaja para los 58 millones de personas de los pueblos indígenas ${ }^{14}$ y los 134 millones de afrodescendientes, por los déficits que tienen en el acceso a servicios y las condiciones de vida, entrecruzados y potenciados "con los diversos ejes de la matriz de desigualdad social", según el último estudio publicado por CEPAL (2021: 18). En los pueblos indígenas, las desigualdades estructurales políticas, económicas, sociales, ambientales y sanitarias "configuran un escenario de mayor vulnerabilidad y riesgo frente al COVID-19 entre las comunidades tradicionales y los grandes grupos de población indígena asentados en las zonas urbanas, y dificultan la mitigación del impacto socioeconómico", como se ve en cinco países que concentran al $80 \%$ de la población indígena de la

14. Son el $10 \%$ de la población regional en 2018 y pertenecen a 800 pueblos indígenas, registrando mayores patrones de pobreza y exclusión social que el resto de población. Su peso demográfico difiere según países: el mayor porcentaje relativo de personas que se autodefine como indígena con relación al total de población está en Guatemala (43,6\%) y Bolivia (41,5\%), mientras México y Perú ocupan los dos primeras posiciones con el mayor número de indígenas entre 17 países de la región (27 126648 y 8305 184, respectivamente) (CEPAL y FILAC, 2020). 
región y sobre los que se dispone de información censal reciente (Chile, Colombia, Guatemala, México y Perú), dándose limitaciones para poner en práctica medidas clave para la prevención del contagio, porque carecen de acceso a agua potable en la vivienda, hay acceso limitado a servicios de saneamiento básico en la vivienda y un mayor nivel de hacinamiento (CEPAL, 2021: 18).

Segundo, las lucha y las resistencias de los pueblos indígenas y campesinos en América Latina no han cesado desde que irrumpió la conquista y colonización de las naciones europeas en el siglo XV y articuló estos territorios al sistema-mundo capitalista del que hablaba Wallerstein (2005), si bien hay variaciones en el tiempo en cómo enfrentan la opresión, marginación, exclusión y racismo. Entre los procesos de movilizaciones contemporáneas destacan las surgidas a partir de las décadas de 1990 y de 2000 que -aunque con especificidades- se caracterizan por el avance y potenciación en las luchas tradicionales, las reestructuraciones organizativas, la búsqueda de alianzas con otros sectores sociales y la defensa de sus formas de vida y recursos naturales frente al modelo extractivo-exportador, la biopiratería, la desposesión así como la apropiación de formas culturales (Svampa, 2010). Zamosc (2009) destaca que en las reivindicaciones se observa una gran diversidad y estrategias propias de cada contexto, pero también de otros factores relacionados con las estructuras demográficas y socioeconómicas, el cómo se establecen las relaciones entre los pueblos indígenas y los estados y con las tradiciones políticas y culturales que existe en cada contexto.

Tercero, hace años los informes de distintos organismos alertan de que América Latina es una de las regiones con índices más altos de violaciones de derechos humanos. En 2019, el contexto estaba marcado por "la desigualdad, la corrupción, la violencia, la degradación medioambiental, la impunidad y el debilitamiento de las instituciones continuaron siendo una realidad habitual", y en varios países se registraron manifestaciones multitudinarias duramente reprimidas, muriendo al menos 210 personas (Amnistía Internacional, 2020: 3). En 2019 la región siguió siendo la más peligrosa del mundo para los y las defensoras de derechos humanos -entre ellas, líderes y lideresas indígenas- y para quienes ejercían el periodismo: "208 personas perdieron la vida de manera violenta por su labor de defensa de los derechos humanos, y muchas otras sufrieron hostigamiento, criminalización y desplazamiento forzado" (Amnistía Internacional, 2020: 3). En 2020 y en un contexto marcado por la pandemia, la directora de Amnistía Internacional para las Américas cuestionó "ciertas medidas punitivas puestas en marcha por los gobiernos ante la propagación del virus, ajenas a las necesidades urgentes y específicas de la población", y cuyo resultado fue el incremento de las violaciones a los derechos humanos (al menos se constató 60 casos de vulneración de derechos durante las restricciones, como detenciones arbitrarias durante el confinamiento); a menudo "prolongan las tendencias represivas que algunos gobiernos vienen ejerciendo ante demandas básicas de la ciudadanía, pero también ante reivindicaciones históricas en defensa de la protección medioambiental, o de lucha contra el racismo y la violencia de género" (Relatoría Fundación Carolina, 2020: 8). La CIDH manifestó su preocupación ante la especial vulnerabilidad de los pueblos indígenas frente a la pandemia y la necesidad de que los estados adopten medidas específicas y acordes con su cul- 
tura y respeto a sus territorios y condenó actos específicos de violación de derechos humanos en Colombia, Perú, Costa Rica, Estados Unidos, Chile, Nicaragua (2021: 65 y 316).

A continuación presento dos casos que ejemplifican las luchas y resistencias de los pueblos indígenas en los cuales se aprecia la participación de las mujeres indígenas, campesinas y comuneras. En esos ámbitos de movilización se ve cómo enfrentan la violencia al interior y exterior de sus pueblos, y cómo en esos procesos se están construyendo derechos humanos al buscar transformar varias lógicas de dominación interrelacionadas -el capitalismo neoliberal, el colonialismo y el patriarcado-, que les oprimen a ellas y sus pueblos desde los gobiernos y el respaldo que éstos dan a las empresas nacionales y transnacionales para la explotación de los recursos naturales, pues como señala Ortega los estados "tienen a su favor la fuerza de la ley, del discurso oficial y de la violencia 'legal' estatal o paraestatal, para realizar dicho despojo" (2018: 4). Son así luchas que articulan varios niveles de acción: el comunitario en defensa de su tierra, ríos, montañas, árboles, etc.; el de género para enfrentar la violencia contra las mujeres; el nivel organizativo, para crear alianzas para sus causas con otras mujeres, sus organizaciones y también apoyos de Organismos No Gubernamentales y entidades internacionales.

Se trata de luchas situadas que aúnan desde sus cuerpos, conocimientos y tradiciones, procesos de resistencias cotidianas, coyunturales y también construidos en el tiempo para defender a sus comunidades, a la tierra y a la vida, al ser afectadas por distintas formas de explotación de los recursos naturales que ellas constatan a diario por sus trabajos en los bosques, los ríos, la agricultura, etc. Son procesos que se construyen desde lo comunitario porque no aplican las diferenciaciones y las separaciones binarias occidentales de individuo-colectivo, privado-público, naturaleza-ser humano ni tampoco el considerar a la naturaleza como recurso o sólo naturaleza. ${ }^{15}$

Defienden el bienestar presente y futuro de todos, la comunidad y la integralidad entre los seres humanos y la naturaleza como el espacio para construir la convivencia de otra manera que no implique el sometimiento de ésta. Por ejemplo, las machis mapuches entienden que el mapu está conformado por "las aguas, el aire, los seres vivos y muertos, los animales, los espacios, la lengua, la esfera psíquica y espiritual" (Santisteban, 2019: 15); en Vaca Muerta (Neuquén, Argentina) un grupo mapuche declaró "Nuestros territorios no son 'recursos' sino vidas que conforman el Ixofijmogen del que somos parte, no sus dueños" (De la Cadena, 2019: 44); en Honduras las indígenas de un grupo focal al mostrar su preocupación porque se ha secado el agua señalaron: "Qué bonito se siente meter la mano en el río y jugar con el agua, oírla correr. Este sistema extractivista nos ha venido, como se dice vulgarmente, a joder más a las mujeres, por el agua. Nosotros [...] nos abastecemos [...] donde está concesionado el río" (Ortega, 2018: 11), mientras otras dijeron "Nosotras no estamos

15. Marisol de la Cadena sugiere que "los pleitos entre el Estado y los indígenas en los países andinos bien pueden ser la manifestación pública de un desacuerdo ontológico [....] en torno al derecho de aquello que el Estado y las corporaciones practican como Naturaleza", por lo que si solo se identifican estas entidades (montes, ríos, etc.) "sólo por su comunalidad -es decir sólo como naturaleza- la extracción de los recursos se justifica en nombre del bien común" (2019: 43-44). 
solas, nuestros hijos y nuestros nietos van a vivir en esta tierra" y "No queremos que nuestros hijos y nuestros hermanos se conviertan [en] limosneros" (TzulTzul [2020]: 6), o como señala Julieta Paredes: "dentro [de] nuestras formas de vida aquí en Bolivia con fuertes concepciones comunitarias $[. .$.$] hacer nuestro propio fe-$ minismo, pensarnos a partir de la realidad en la que vivimos. No queremos pensarnos frente a los hombres, sino pensarnos mujeres y hombres en relación a la comunidad" (2014: 79).

Otro aspecto a destacar es que son las propias mujeres indígenas quienes alzan sus voces, liderando incluso muchas de las acciones de lucha y enfrentando también descalificaciones y asumiendo los riesgos junto a sus pueblos. Son conscientes de ello como se ve, por ejemplo, en las palabras de Martha Sánchez Néstor (2004): "[...] quizás hoy, muchos no lo observen, otros lo desdeñen, algunos más descalifiquen, pero a mis hermanas indígenas les digo: quién si no nosotras mismas para seguir apropiándonos de nuestras voces". También el que las luchas de unas mujeres indígenas inspiran a otras para organizarse y reclamar frente a los abusos y a opresiones que padecen en tanto mujeres, indígenas, integrantes de pueblos a los que se trata de despojar de sus recursos, sumándose a llamados como el formulado por Bety Cariño en 2009 y que consta en el epígrafe de esta sección: "Ya basta de que sigan acabando con nosotros".

\section{4.l México}

Aquí refiero las experiencias de lucha que hacen las mujeres de los colectivos El Rebozo, Zapateándole, Lente Flotante, En cortito que's pa largo (2014), en el prólogo de la edición mexicana del libro de J. Paredes (2014). Son 12 historias que reseñan diversos eventos ocurridos entre diciembre de 1993 y agosto de 2011, mostrando la memoria de sus procesos auto-organizativos de "mujeres luchadoras que, sin nombrase a sí mismas como feministas comunitarias, han sembrado semillas que tienen mucho en común con las luchas y las búsquedas del feminismo comunitario que propone Julieta Paredes" (El Rebozo et al., 2014:12). Es su "recorrido histórico a través de ejemplos de las muchas luchas, entrelazadas entre sí, que mujeres cotidianas y anónimas libran todos los días [...], defendiendo su palabra, su tiempo, su memoria, su espacio y su cuerpo"; son historias de "violencia y resistencia cotidiana que deben contarse para que no vuelvan a repetirse" (El Rebozo et al, 2014: 28). A título ilustrativo destaco:

- La inclusión, en el primer boletín del Ejercito Zapatista de Liberación Nacional (EZLN), de la Ley Revolucionaria de Mujeres (diciembre de 1993), donde las mujeres indígenas rebeldes, defendiéndose de los machismos institucionales o cotidianos, asientan "con determinación que las mujeres tienen derecho, sin importar su raza, su credo o su filiación" a participar en la lucha revolucionaria, en los asuntos de la comunidad, recibir un sueldo, no ser golpeadas, ocupar cargos de dirección.... (El Rebozo et al., 2014: 12).

- Acciones como la de enero de 1998, cuando tras la masacre de 45 indígenas en la comunidad de Acteal (Chiapas), el ejército mexicano intentó ocupar la comunidad tzotzil de Xoyep que hace semanas hospeda a indígenas desplazados de sus comunidades; frente a ese 
intento de ocupar "el Campamento de Paz, instintivamente todas las mujeres, pertenecientes a la organización de la sociedad civil Las Abejas, forman unos cordones de paz y hacen que los soldados se replieguen"; descalzas y "armadas sólo de sus manos y de la firmeza de sus corazones, enfrentando al mayor símbolo patriarcal del sistema político actual: el ejército equipado con las peores herramientas de muerte para imponer su poder" (El Rebozo et al., 2014: 13-14).

- La reunión, en noviembre-diciembre de 2002, en Oaxaca de más de 350 delegadas de 22 países en la Primera Cumbre de las Mujeres Indígenas de América; produjeron en forma colectiva un documento intitulado "'Género desde la visión de las mujeres indígenas' que da pautas para rastrear raíces de las cosmovisiones ancestrales, a la vez que para revisar las re-conceptualizaciones y resignificaciones de ciertos términos feministas", siendo "un proceso único de intercambio, pero sobre todo un laboratorio político y cultural" (El Rebozo et al., 2014: 14).

- 3 y 4 de mayo de 2006. Como castigo por la resistencia del Frente de Pueblos en Defensa de la Tierra (que en 2002 logró parar el proyecto de un aeropuerto en su territorio), así como para frenar la iniciativa de la Otra Campaña que articula y hermana las luchas anticapitalistas promovidas por el EZLN, "Ios tres niveles de gobierno" lanzaron una grave represión política: se "violaron los derechos fundamentales de más de 200 personas, lesionándolas y torturándolas, al tiempo que los efectivos policíacos detuvieron, golpearon, humillaron y violaron sexualmente a 47 mujeres" (EI Rebozo et al., 2014: 16).
- Los asesinatos en el Municipio Autónomo de San Juan Copala: el 7 de abril de 2008 son asesinadas a balazos mientras se dirigen a Oaxaca a un encuentro de derechos humanos, Teresa Bautista Merino (24 años) y Felícitas Martínez Sánchez (20 años), locutoras de la radio comunitaria La Voz que Rompe el Silencio; el 27 de abril de 2010 Bety Cariño, indígena mixteca, fue asesinada junto al finés Jyry Jaakkola, al participar en una caravana humanitaria de solidaridad en ese municipio.

- En marzo de 2010 las mujeres de la Montaña y Costa Chica de Guerrero realizaron el Primer Encuentro de Mujeres Indígenas de la Región de la Montaña, presentando ante las autoridades comunitaria su trabajo organizativo a lo largo de casi tres años; los distintos puntos se plasmaron en la Carta de los Derechos de las Mujeres "que se puede cumplir gracias a que se cuenta ya con un sistema de justicia comunitaria." (El Rebozo et al., 2014: 23).

- El I5 de Abril de 2011: "iLa tierra no se vende, se ama y se defiende!" Las mujeres de la comunidad purépecha de Cherán (Michoacán), "hartas de ver a sus maridos, hijos y hermanos desaparecidos o muertos, así como a sus árboles, troncos de vida, cortados por los talamontes del crimen organizado", levantan su voz y "logran empujar al resto de la comunidad para levantarse en contra de estos abusos". Así lo relatan algunos testimonios de las mujeres de Cherán:

Ese día venían bajando madera de El Calvario y fueron las mujeres las que se atravesaron y detuvieron los carros, amarraron a los hombres que conducían y quemaron sus carros [...] El tra- 
bajo de las mujeres en esta lucha ha sido fundamental. Es importante tomar en cuenta a todos los miembros de la comunidad. Antes iban sólo los hombres a quejarse y a defender los recursos, pero fueron nuestras mujeres quienes lograron estimular la conciencia de las demás personas del pueblo. (El Rebozo et al., 2014: 26-27)

\subsection{Honduras}

En este país centroamericano las luchas de los pueblos indígenas y campesinos para defender sus territorios y fuentes de subsistencia se dan frente al Estado y las empresas extractivas que han recibido concesiones para extraer minerales e hidrocarburos y la generación de energía eléctrica. En el mapeo realizado por la Unión Internacional para la Conservación de la Naturaleza (UICN) indica que solo en el territorio indígena y afrodescendiente "existen 54 concesiones mineras, 36 proyectos de generación de energía eléctrica y la única concesión de hidrocarburos dentro de estos territorios", como consta en el documento elaborado por la Universidad Nacional Autónoma de Honduras (UNAH), el Foro Social de Deuda Externa y Desarrollo de Honduras (FOSDEH) y OXFAM (2019: 6).

La violencia contra las comunidades que se oponen a ese incremento de los proyectos es alta y se agudiza con la militarización del país desde 2009, además de la criminalización que se hace de la protesta y "la impunidad en la que se dan las constantes agresiones en contra de los defensores y las defensoras de los derechos humanos, en su mayoría, relacionados con la defensa del medioambiente, de la tierra o del territorio" (UNAH, FOSDEH y OXFAM, 2019: 7). Preocupa en especial la situación de las mujeres porque, por ejemplo, "de cada 100 mujeres, 86 no tienen acceso a la tierra, lo que conlleva un gran porcentaje de mujeres involucradas en procesos de recuperación de tierras" (Proyecto Brigadas Internacionales [PBI], 2020). En 2015 se registraron más de dos mil agresiones a mujeres defensoras y en 2016-2017 hubo 1.232 agresiones contra mujeres defensoras, sus familias y sus organizaciones: el $60 \%$ de los victimarios reconocidos fueron policías, militares, autoridades del Estado o empresas (UNAH, FOSDEH y OXFAM, 2019: 7). Entre los ejemplos más graves de hasta dónde pueden llegar las acciones para acallar las protestas están los reiterados asesinatos de los y las líderes indígenas: entre 2015 y 2018 se produjeron al menos 31 asesinatos de personas defensoras de los derechos, y 2016 fue uno de los años más mortíferos y entre 2018-2019 seis mujeres fueron asesinadas (PBI, 2020:6).

Una de esas personas fue Berta Cáceres, reconocida líder indígena lenca, que sufrió persecución durante años y fue asesinada el 2 de marzo de 2016 por su lucha en la defensa del territorio lenca contra el proyecto hidroeléctrico "Agua Zarca", concesionado al Grupo DESA (Desarrollos Energéticos Sociedad Anónima) para explotar el Río Gualcarque en la comunidad de Río Blanco. Cáceres encabezó luchas comunales con dos dinámicas: "una lucha anticapitalista en tanto busca seguir conservando la calidad comunal de la tierra y anti patriarcal, pues busca garantizar condiciones para la vida libre de violencia para las mujeres" (TzulTzul, [2020]: 4), y lo hizo como integrante y luego Directora del Consejo Cívico de Organizaciones Populares e Indígenas de Honduras (COPINH), entidad que fundó en 1983 con 
otras personas lenca para la defensa de ese pueblo de la zona sur occidental y de otros pueblos indígenas de Honduras: "cuatrocientas comunidades, en su mayoría lencas, organizaciones también de mujeres, de jóvenes y comunidades campesinas", como señaló la propia Cáceres (2007). En base al ensayo de Gladys TzulTzul [2020], paso a caracterizar esa lucha:

- "Presenta un espectro de reivindicaciones plurales que activaron en demanda, y también como recuperación y defensa de las comunidades articuladas como COPINH" (TzulTzul [2020]: 7)

- Consiguieron canalizar energía social para que sus luchas tuvieran alcance nacional y integraran el reclamo de la tierra comunal frente a las pretensiones hidroeléctricas, "eventos para exigir el respeto y dignidad de los pueblos indígenas en el contexto del $\mathrm{V}$ centenario; acciones concretas para evitar la tala de bosques", así como los denominados Tribunales de mujeres para juzgar la violencia contra las mujeres y las niñas. Se trata de luchas de las mujeres "plurales y abarcativas, es decir no son segmentadas":

Para el COPINH, el que se luchara por la defensa de la tierra y al mismo tiempo que por evitar que los maestros de escuela ejercieran violencias contra las niñas y las mujeres o que los hombres articulados al movimiento ejercieran violencia contra sus compañeras de luchas, representa una muestra de las formas que cobran las luchas de las mujeres y la energía que empujan desde dentro de la organización. (TzulTzul [2020]: 7)

- El testimonio de Melisa Cardoza, una de las mujeres participantes, indica que: "existía una cultura de defensa de las mujeres. Defensa que consideraba que no hay separación entre la violencia do- méstica y la violencia del capitalismo. Berta Cáceres era fundamental para estos procesos, ella como coordinadora apoyó e impulsó"; por lo que su asesinato no solo quiere "extinguir la dirigencia de COPINH, sino que también pone en riesgo y socaba el proceso creativo y plural en la que una organización campesina y de base desarrolló y construyó lo que ellos mismos denominan como puntos de lucha" (TzulTzul [2020]: 7 y 2)

- En el contexto del golpe de Estado que vivió el país en 2009, el COPINH organizó la primera Corte Popular de Mujeres, y tenía como antecedente que varios años antes las mujeres acudían a esa entidad a poner denuncias. Las resoluciones no rodean "la institucionalidad oficial de la justicia sino que concurría a formas autorregulatorias", preventivas de la violencia y que complementaban la denuncia con procesos de educación. Melisa Cardoza comenta:

El COPINH ha tenido una lista larga de victorias y entre ellas se cuentan Las Cortes Populares de Mujeres, pues logramos hacer justicia por nosotras mismas [...] cuando organizábamos cortes populares de mujeres era bien interesante, sabíamos de los problemas de violencia al interior de nuestra organización y también por parte de los maestros y de los funcionarios públicos. Decidimos hacerlo. Como justicia y también como educación para la prevención [...] La Corte se establece como un espacio de denuncia pública. Tan pública que hasta lo pasábamos por la radio y ahí se establece una mesa de juezas que van a ser invitadas. Se cuidaba mucho que no fueran feministas en el papel de redentoras. Se sabía que no era un movimiento homogéneo, por ello participaron feministas que también estaban luchando en sus espacios. (TzulTzul [2020]: 7) 


\section{Reflexión final}

En el mundo actual son cada vez más evidentes el empobrecimiento y las desigualdades que el sistema capitalista provoca, porque no todos los individuos y colectividades resultan ganadoras y dueñas de las riquezas y máximos beneficios que pregona particularmente la globalización neoliberal y de mercado. En cualquier región del planeta hay muestras de la acumulación del capital, de los bienes y los recursos en pocas manos mientras cada vez se incrementa el número de personas que ven disminuir sus condiciones mínimas de vida, además del propio deterioro ambiental por la explotación que para el desarrollo y la modernización se hace de los recursos del planeta como si fuesen infinitos.

Frente a ese panorama hay otro que surge en los márgenes y que señala la práctica social y política de la rebeldía y la resistencia: son las luchas de las mujeres indígenas y sus pueblos, para día a día enfrentar las lógicas hegemónicas de la acumulación del capital y la destrucción que genera en sus territorios. A pesar del alto riesgo que supone para sí mismas porque pueden sufrir distintas violencias e incluso ser asesinadas-, las luchas comunitarias que emprenden en lo cotidiano y en procesos organizativos desde sus referentes culturales y epistémicos, buscan construir bienestar y convivencia preservando la vida.

Los casos de las indígenas de México y de las que integran el COPINH en Honduras, caracterizados en páginas anteriores, permiten ver las acciones concretas de lucha y resistencia que plantean en procesos que se desarrollan desde abajo y a través de los cuales se está generando derechos humanos. En la medida que se entablen y fortalezcan vínculos horizontales y solidarios, se está enfrentando la dominación capitalista, patriarcal y colonial que caracteriza a las sociedades en América Latina, sobre todo si se estas tramas de relaciones sociales transforman las opresiones en todos los niveles. Por otra parte, los casos reseñados muestran también el peso que soportan dentro y fuera de sus comunidades las mujeres indígenas, señalando además la fortaleza y creatividad que tienen, junto con la capacidad de articular alianzas con otras mujeres y entidades porque nadie sobra en esta lucha.

\section{Bibliografía}

Acosta, A. (2019). "La renovada dependencia extractivista. Violencia sobre cuerpos, territorios y visiones", en R. Silva Santisteban (Ed.), Mujeres Indígenas frente al Cambio Climático, Lima, IWGIA, 17-34.

Allard, R. (2015). "Medicamentos esenciales y Acuerdo sobre los ADPIC: colisión entre el derecho a la salud y el derecho de propiedad intelectual", Salud colectiva, 11 (1), 9-21.

Banco Mundial (2021). "Pueblos indígenas", en web del Banco Mundial, recuperado el 25 de agosto de https://www. bancomundial.org/es/topic/indigenouspeoples

Berger, M. y Carrizo, C. (2018). "Governance agrobiotecnológica y justicia ambiental. Tensiones en torno a la liberalización de transgénicos en Brasil, México y Argentina", en H. Cuevas Valenzuela, D. Julián Véjar, J. Rojas Hernández (Eds.), América Latina: expansión capitalista, conflictos sociales y ecológicos, Santiago [Chile], RiL Editores y Universidad de Concepción, 193-215. 
Cáceres, B. (2007). Discurso en el VII Taller Internacional sobre Paradigmas Emancipatorios, realizado en La Habana (Cuba), recuperado el 3 de agosto de 2021 de https://capiremov.org/es/analisis/ berta-caceres-4/

Casanova, L. (2021). "Megaproyectos y conflictos ecoterritoriales. El caso del Tren Maya", Relaciones Internacionales, (46), 139-159.

CEPAL Comisión Económica para América Latina y el Caribe (2021), Panorama Social de América Latina, Santiago [Chile], Naciones Unidas.

CEPAL y FILAC Fondo para el Desarrollo de los Pueblos Indígenas de América Latina y el Caribe (2020). Los pueblos indígenas de América Latina - Abya Yala y la Agenda 2030 para el Desarrollo Sostenible: tensiones y desafíos desde una perspectiva territorial, Santiago [Chile], Naciones Unidas.

CIDH Comisión Interamericana de Derechos Humanos (2021). Compendio de la Comisión Interamericana de Derechos Humanos sobre verdad, memoria, justicia y reparación en contextos transicionales, aprobado por la Comisión Interamericana de Derechos Humanos el 12 abril de 2021, OEA (OEA/Ser.L/V/II. Doc. 121, 12 abril 2021).

Conferencia Internacional Americana (1948). Declaración Americana de los Derechos y Deberes del Hombre (1948), Organización de Estados Americanos (OEA) - Comisión Interamericana de Derechos Humanos (CIDH), consultado el 25 de agosto de 2021 en http://www.oas.org/es/ cidh/mandato/Basicos/declaracion.asp

Cuevas, H. y Julián, D. (2018). "Capitalismo en el primer plano: tensiones en el desarrollo latinoamericano (una introduc- ción al debate)", en H. Cuevas Valenzuela, D. Julián Véjar, J. Rojas Hernández (eds.), América Latina: expansión capitalista, conflictos sociales y ecológicos, Santiago [Chile], RiL Editores y Universidad de Concepción, 11-24.

De la Cadena, M. (2019). "Protestando desde lo incomún", en R. Silva Santisteban (Ed.), Mujeres Indigenas frente al Cambio Climático, Lima, IWGIA, 35-48

El Rebozo, Zapateándole, Lente Flotante, En cortito que's pa largo (2014). "Prólogo", en J. Paredes, Hilando fino desde el feminismo comunitario, 2da. edición, Ciudad de México, Cooperativa el Rebozo, Zapateándole, Lente Flotante, En cortito que's pa largo y AliFem AC, 11-36.

Galafassi, G. (2018). "Revitalización del debate sobre la acumulación primitiva y la reproducción ampliada. Su aplicación para el análisis de la conflictividad social en América Latina", en H. Cuevas Valenzuela, D. Julián Véjar, J. Rojas Hernández (Eds.), América Latina: expansión capitalista, conflictos sociales y ecológicos, Santiago [Chile], RiL Editores y Universidad de Concepción, 25-50.

Galafassi, G. y Riffo, L. (2018). "Del sueño de Cristóbal Colón al hoy llamado «extractivismo». Peripecias y avatares de un largo y continuo proceso de expropiación para la acumulación: una necesaria discusión crítica", Theomai, (38), 232-245.

Gallardo, H. (2007). Teoría crítica: matriz y posibilidad de derechos humanos, Murcia, Francisco Gómez Editor.

Gudynas, E. (2018). "Disputas entre variedades de desarrollo y el cuadrilema de la globalización", en H. Cuevas Valenzuela, D. Julián Véjar, J. Rojas Hernández (Eds.), América Latina: expansión capitalista, conflictos sociales y ecológicos, San- 
tiago [Chile], RiL Editores y Universidad de Concepción, 173-191.

Gudynas, E. (2019). "Cambio climático, extractivismos y género: crisis entrelazadas dentro del desarrollo", en R. Silva Santisteban (Ed.), Mujeres Indigenas frente al Cambio Climático, Lima, IWGIA, 49-72.

Harvey, D. (2003). El nuevo imperialismo, Madrid, Akal.

Houtart, F. (2017). "La agricultura campesina e indígena como una transición hacia el Bien Común de la Humanidad: el caso del Ecuador", Working Papers CriDIS, (54).

Moore, J.W. (2016). "El fin de la naturaleza barata: o cómo aprendí a dejar de preocuparme por 'el' medioambiente y amar la crisis del capitalismo", Relaciones Internacionales, (33), 143-174.

Naciones Unidas (1999). Declaración sobre el Derecho y el Deber de los Individuos, los Grupos y las Instituciones de Promover y Proteger los Derechos Humanos y las Libertades Fundamentales Universalmente Reconocidos [Declaración sobre los Defensores de los Derechos Humanos], (A/RES/53/144), New York.

Ortega, A. (2018). "Mujeres indígenas de La Paz contra el despojo del agua", Análisis, (7), recuperado el 2 de agosto de 2021 de http://ibrary.fes.de/pdf-files/ bueros/fesamcentral/14932.pdf

$\mathrm{PBI}$ Proyecto Brigadas Internacionales (2020). La defensa de la tierra tiene nombre de mujer. Informe elaborado para el Examen Periódico Universal (EPU) a Honduras en mayo de 2020, recuperado el 3 de agosto de 2021: https://pbi-honduras.org/sites/pbi-honduras.org/files/publications/EPU\%20 ESP.pdf?utm_source=News\&utm_
campaign=f42f10c97d-EMAIL_ CAMPAIGN_2020_02_19_01_01\&utm_ medium=email\&utm_term=0 c529e82a92-f42f10c97d-110706135

Paredes, J. (2014). Hilando fino desde el feminismo comunitario, 2da. edición, Ciudad de México, Cooperativa el Rebozo, Zapateándole, Lente Flotante, En cortito que's pa largo y AliFem AC.

Rojas, J. (2018). "Vulnerabilidad socioecológica y espacios descolonizados en América Latina en la era Antropoceno", en H. Cuevas Valenzuela, D. Julián Véjar, J. Rojas Hernández (Eds.), América Latina: expansión capitalista, conflictos sociales y ecológicos, Santiago [Chile], RiL Editores y Universidad de Concepción, 147-172.

Sánchez Néstor, M. (2004). "Mujeres indígenas: vivencias y retos", El sur [edición digital del periódico de Guerrero, México], recuperado el 3 de agosto de 2021 de https://flacsoandes.edu.ec/web/imagesFTP/MARTHA_SANCHEZ_N.pdf

Sánchez Néstor, M. (2011). "Amuzga, feminista, ciudadana", Nexos, recuperado el 15 de agosto de 2021 de https://www. nexos.com. $m x /$ ? $p=14207$

Sánchez Rubio, D. (2018). Derechos humanos instituyentes, pensamiento crítico y praxis de liberación, Madrid, Akal.

Sánchez Rubio, D. y Solórzano, N. (2004). "Introducción", en D. Sánchez Rubio, N. Solórzano y I. V. Lucena (Eds.), Nuevos colonialismos del capital. Propiedad intelectual, biodiversidad y derechos de los pueblos, Barcelona, Icaria, 11-70.

Santos, B. de S. (2018). "Los derechos humanos, una frágil hegemonía", en Construyendo las epistemologías del sur: para un pensamiento alternativo de alter- 
nativas, Ciudad Autónoma de Buenos Aires, CLACSO, 209-222.

Secretaría de la Corte Interamericana de Derechos Humanos CIDH (2020). Comunicado [Caso Comunidades Indígenas Miembros de la Asociación Lhaka Honhat (Nuestra Tierra) Vs. Argentina], Corte IDH_CP-24/2020 Español, recuperado el 20 de agosto de 2021 de https://www. corteidh.or.cr/tablas/alerta/comunicado/ cp-24-2020.html

Silva Santisteban, R. (2019). "Prólogo", en R. Silva Santisteban (Ed.), Mujeres Indígenas frente al Cambio Climático, Lima, IWGIA, 7-15.

Stavenhagen, R. (2006). "Los derechos de los pueblos indígenas: esperanzas, logros y reclamos", en M. Berraondo (Coord.), Pueblos indigenas y derechos humanos, Bilbao, Universidad de Deusto, 21-28.

TzulTzul, G. ([2020]). "El deseo que moviliza la lucha de las mujeres comunales en Honduras", CLACSO, recuperado el 15 de agosto de 2021 de https://www.clacso. org/el-deseo-que-moviliza-la-lucha-delas-mujeres-comunales-en-honduras/

UNAH Universidad Nacional Autónoma de Honduras, FOSDEH Foro Social de Deuda Externa y Desarrollo de Honduras y OXFAM (2019). Territorios en Riesgo II. Minería, generación de energía eléctrica e hidrocarburos en Honduras, recuperado el 15 de agosto de 2021 de https://honduras. oxfam.org/territorios-en-riesgo-2

Wallerstein, I. (2005). Análisis del sistema-mundo: Una introducción, Madrid, Siglo XXI Editores.

Zamosc, L. (2009). "Ciudadanía indígena y cohesión social en América Latina", en P. Ospina, O. Kaltmeier y C. Büschges
(Eds.), Los Andes en movimiento. Identidad y poder en el nuevo paisaje político, Quito, Universidad Andina Simón Bolívar Sede Ecuador, Universidad de Bielefeld, Corporación Editora Nacional, 13-39. 